\title{
The Hot Line*
}

\author{
C. A. H. WATTS
}

14 October 1970 .

Ibstock, Leicestershire

C. A. H. WATTS, O.B.E., M.D., F.R.c.G.P., General Practitioner

ing. We are both highly suspicious of each other. I feel that he hoards beds as a miser hoards money. He feels that I am trying to put one across him and get rid of an awkward patient. The gulf, one might almost say the enmity, between the young houseman and the G.P. is traditional and to some extent understandable. The work and backgrounds of the two parties are poles apart; each cherishes a somewhat caricatured picture of the other, and there is little chance to improve the relationship by personal contact. This seems to be an unsatisfactory method for admission to hospital. Other ways are available, such as via the casualty department or through a bed bureau or a registrar.

A bed bureau has the great advantage that it saves time for both the hospital staff and the G.P. Moreover, it could save a great deal of damage to the general practitioner's arteries, which must suffer considerably as valuable time drags on while the switchboard searches round the hospital for an elusive houseman and the round of visits comes to a halt. It is possible to spend half an hour or more on an admission. On the other hand, the bed bureau is an impersonal method. I like to feel that I have been in contact with one of the doctors who will be looking after my patient. If I had the choice of a method of admission I would certainly opt for contact through a registrar. If the registrar had his own secretarial help this could save a great deal of time. The registrar tends to stay at the hospital for a few years, and, with a secretary to help him, I feel sure that between them they would be able to get to know the G.P.s of the area and be able to sort out the sheep from the goats; unfortunately there are a few goats. I think that there may well be a place for a black-list. This is done in the teaching world. In this way our children are protected from sexual deviants. A black-list in print is perhaps a bit invidious, but in the mind of the registrar or his secretary it could be quite useful.

I find it hard to understand why some G.P.s hide behind an ex-directory number. This strange habit has become almost universal and is bad for our image, not only among the patients but also with consultant colleagues. My working rules are as follows. If I am not on call I don't answer the 'phone myself. Whoever picks it up says I am engaged-never that I am outand nine times out of ten whoever does answer it can deal with the problem; but if I am needed I will take the call. I don't suppose this happens more than once a month, and often I can help with very little trouble, whereas a stranger to the problem would be in difficulties. One night when another member of the rota was on call I received a message that a child had been killed in one of our villages. It is indeed hard to find any means to console in this situation, but the family doctor who knows the people concerned is in a better position to help than any stranger. I went over at once to see the unhappy parents. If I had been ex-directory I could not have helped in this situation, and this was real family medicine. When I want to have a social chat with a fellow G.P. I find it a bit irritating to be told to ring his partner. It must be even more frustrating for the consultants who wish to contact us G.P.s out of hours about a patient they may have just seen, as talks like this can be most useful. I feel very strongly about this gimmick, which is as wrong as it is unnecessary.

There is a real place for telephone medicine so long as the caller is not upsetting surgery time or just trying to jump the queue. Many minor problems can be dealt with in this way. The key here is that the inquirer must be left satisfied that the problem has been dealt with adequately, and not with the unpleasant feeling that the doctor is just too idle to make a house call. 
Secretaries and wives can be overprotective towards their doctors, so much so that it becomes quite a problem to see the doctor. One Tuesday morning a friend rang up her G.P. to make an appointment that evening. "The doctor cannot see you today," was the crisp, almost joyous rejoinder, "Nor can he see you any day this week." People who put in emergency calls after hours are sometimes so intimidated; a very sick patient can be neglected. A friend of a young doctor had a different problem with her G.P.'s receptionist. She would ring up and ask for an appointment to have one of her small children seen, and she was then questioned about signs and symptoms and finally told to call for a prescription. In the course of 12 months she never managed to see the doctor, and such is the loyalty of the public to our profession she had to seek her medical friend's assurance that it was reasonable to change over to a doctor who was more accessible. Apart from emergency cases, which must be seen promptly, and cases that are clearly not urgent, all patients in general practice should be seen by some doctor in the firm in 24 hours, and all outpatients at hospital should be seen in a week.

\section{Postal Communications}

A letter can be too short, too long, beside the point, or illegible. When a G.P. writes to a hospital his letter should contain certain basic information. There should be a list of signs and symptoms, and he should have the courage to name a diagnosis or give a list of possible diagnoses. Most important from the hospital's standpoint, he should list all the drugs the patient is taking. He should also name any allergies or points of special interest. The patient may have a low pain threshold or be an epileptic or hypertensive. Whenever possible letters should be typed.

I think there are five main points which the G.P. requires in the letter from the hospital-the diagnosis, a list of investigations performed, the treatment given in hospital, the treatment to be given at home, and when the patient is likely to be fit for work. It is virtually impossible to get a patient back to work after he has been in hospital unless the consultant has suggested when he will be fit for work.

There are a few frills which make letters more palatable. It is rather nice to know that one's own letter has been read. The G.P. gets quite a kick if the hospital letter confirms his diagnosis, especially if he has chanced his arm and opted for something unusual like a ruptured gall bladder or a painless coronary thrombosis. A twist of humour is always welcome; it can make our day.

\section{Second-hand Messages}

These are the most unsatisfactory forms of communication; facts are so likely to be distorted and embroidered as they get passed on. How irritating it is to get a message to come and see Mrs. Smith at once. She is said to be very ill, and yet the messenger on the 'phone or the doorstep can give no indication of what is wrong or just how urgent the case is. It is equally tiresome for us in general practice to have to describe some complicated case to a nurse because the houseman is scrubbed up and cannot get to the 'phone.

\section{Doctors and their Patients}

Confronted by any patient the first thing to do is to establish confidence, and, secondly, to do this one must learn to speak in a language that the patient can understand. In general practice, where the patient is already known, confidence is likely to be there from the outset. If, however, the patient is new, frightened, or embarrassed time must be taken to get round these difficulties. Any doctor can cope with the pleasant, grateful, and easygoing patient, but it takes skill to win the confidence of those who are fearful, on the defensive, or even paranoid.

All doctors must beware of becoming case-hardened. I think it can be taken for granted that to visit a doctor is always a frightening experience, and a hospital appointment may be quite terrifying. Confidence must be established, and it need not take an eternity of time. A patient once said of a holiday locum, "She is never in a hurry but she never wastes a minute"; a great compliment to her method of working. Whatever time is spent with the doctor the patient must be made to feel that he or she is the only person who matters and that the doctor's entire attention is on the patient and his problems. To know the doctor's name is most important. This is almost routine in general practice but rare in hospitals. In some clinics the doctor's or nurse's name is written on a card or a label. Unless the writing is large enough to be easily read it is a complete waste of time, as small print is illegible to a worried patient.

If the doctor's name is long or unfamiliar to our Anglo-Saxon minds, then we should follow the example of some industries and produce a simplified version.

Names in the U.K. and Suggested Alternatives

Velt Huisen Van Zenten

Szczurowsk Nxulmalo

Dr. Van

Dr. Denis (his forename) Dr. Marlow

The sort of complaint that we often hear from patients who have to attend the outpatient department is, "I have been five times, and every time I see a new doctor." This is very disconcerting for the patient and damages confidence, and it can be largely circumvented if the patient knows whom he is seeing. I am sure that this problem can be obviated quite easily if the deputy says, "I am Dr. Brown, Dr. Jones's registrar. I know all about you from your notes." Confidence in the G.P. is not enhanced by the custom of writing out a prescription while the patient is talking and handing it to him before he has even finished his history. This does happen. There are a few hypermanic patients in every practice whose eloquence is an embarrassment, but these birds are really very rare. At the end of a consultation it is a good idea to ask the patient, "And is there any other problem ?" This question sometimes gives the timid person a chance to say something he really wanted to get off his chest but was holding back as he felt the doctor was really too busy to be troubled by it. The patient seeks and deserves undivided attention; on the other hand, over-familiarity should be avoided. The patient as well as the doctor has a name. To call a young woman popsy and an old man grandpa is both slovenly and discourteous.

My second point is to speak in a language that the patient can understand. Now this may sound obvious and easy, but is is not. People under emotional stress are ready to misinterpret what has been said and to think the worst. A year or so ago there was a rabies scare in the south. A woman consulted her doctor about her small girl. They had had a case of rabies at the nursery school and she understood you could get it from a mere scratch. Incredulous, the G.P. rang the director of the school. They had in fact a case of scabies. Words must be chosen with the greatest care, and always use the most simple terms. A woman with a patch of unpigmented skin on her arm burst into tears as she showed it to me. One of my partners had quite correctly called it leucoderma. She had heard leukaemia, and hence her despair.

Patients going into hospital for an operation should so far as possible have the procedure explained to them; this is especially important in gynaecology. I feel very strongly that someone should make it his business to spend a few minutes telling the patient what is going to happen, and then again after the operation the surgeon or his registrar should explain what has been done. Almost every patient assumes that there is a cancer unless informed otherwise. I think that it should be a part of his training in man-management for the houseman to be taught how to talk to the patient before the operation. The 
surgeon who is doing the job is not always the best person to explain in advance. His is a technical job, and he may well not want to be emotionally involved. An eminent heart surgeon once told me that when he was interviewing two parents before a tricky operation on their child he was told by the father, "Do your best for him doctor, he is all we have." This was the last thing the surgeon wanted to know. In general there seems to be a conspiracy of silence for the patients who enter hospital. Time and again patients come home not knowing what has happened to them or how much has been taken away. I realize that many folk forget or play down what they have been told, but some are quite reliable witnesses.

Being confronted by a patient with a fatal illness is always an unpleasant part of our work. I think that all concerned subconsciously feel guilty because they can do so little to help, and the whole issue may well be evaded. A farmer came to see me with a large spleen and I referred him to hospital, where the organ was removed. He was a jolly fellow and a very good patient. He cracked jokes with all and sundry and was one of the most popular patients in the ward. Four years later I saw him again with pyrexia of unknown origin, and once more he went into hospital. He was found to be in the terminal stages of leukaemia. He felt desperately ill and all his old sparkle had gone. He lay in bed almost completely ignored by the staff. Sadly he told his wife, "I know they can do nothing for me this time. They do not even speak to me." I am sure that the cruelty was unintentional. In family practice this could hardly arise, as the G.P. who visits is responsible on his own for what goes on; he cannot evade the problem. In hospital the responsibility can easily be shelved, in that each member of staff thinks that someone else will do it, so that it never gets done at all; thus no one befriends the dying man when he most needs to be befriended.

I have said quite a lot about not saying enough to patients. One can say too much. Never joke about a person's illness. When I was working in South Africa a young soldier was admitted to hospital as an emergency. He had acute schizophrenia, and the voice of God had ordered him to amputate his penis. He did this with a razor blade while having a bath. A surgeon was called in to see him, and he jokingly remarked that he had cut off the wrong bit. That night the patient broke a window and tried to complete the job with broken glass. Jokes are nearly always dangerous.

Daily visits to children in hospital are now a routine part of treatment. I sometimes think that the pendulum has swung too far, not for children but for adults. I would suggest that there should be no visiting for patients who have had a major operation for at least 48 hours. Those early visits give neither comfort nor pleasure to anyone. The patient may well not remember the visit at all, and the relatives are appalled at the sight they see. If there was a "No-visiting" rule a small minority would suffer more by being sent for in a hurry, but the vast majority of patients and their relatives would have a far less traumatic time.

I have one last suggestion for the hospital outpatient department. In our modern multiracial society I think that there should be a panel of interpreters available. The appointment form should contain such questions as, "Does the patient speak English ?", "If not, can he bring an interpreter ?", and "If he wants an interpreter at the hospital, what language does he speak ?"

\section{Conclusion}

The title "The Hot Line" implies a sense of urgency, urgency engendered by a crisis, and in medicine today there are crises galore. The profession, in the glare of modern mass media, has slipped from its time-honoured pedestal; public relations have deteriorated. In the States the doctor is actively hated, and sued whenever possible. They say we are always 10 years behind the States. The long waiting-lists at our hospitals are frustrating for all concerned, and the chronic lack of funds for better hospitals and equipment adds to the general dissatisfaction which is so often expressed by almost mass emigration of our doctors.

A hot line to Whitehall seems out of the question at the moment, but between ourselves and our patients it costs little and could go far to improve the services as a whole. Most people are familiar with the nineteenth century picture of "The Doctor" painted by Sir Luke Fildes. Here was a doctor of about 1880 . He was surely an ancestor to all of us. He could have been a surgeon, a consultant physician, or Sir James Mackenzie himself. The differentiation in our work had hardly begun. He had three or four drugs which worked, but compared with us he was therapeutically sterile. He had few diagnostic aids beyond those in his five senses. Yet at that time the prestige of the doctor was very high. His strength lay in his simple psychology, his man-management, and yet he had never heard of Freud. Amidst the thrill and excitement of modern medicine don't neglect that powerful tool which costs so little beyond time, sympathy, and a listening ear. It has many names-the sound rapport situation, the holistic approach, a good bedside manner -call it what you will.

" $L$ 'Amour de la medicine fait le savant. L'Amour du malade fait le medicin."

\section{One Hundred Years Ago}

PoISONOUS SILK Gloves.-Dr. J. T. Dickson writes in a daily pa er: On Saturday last a patient called upon me and exhibited her hands covered with very irritable blebs or blisters. After minute examination and questioning for cause, she told me that during the week she had purchased in Marylebone a new pair of silk gloves for two shillings, had worn them during a journey to Manchester and back, and that her hands had borne these vesications ever since. She wore the left glove more constantly than the right. I desired her to bring the gloves to me, and I found that they were of good quality spun silk, dyed of a light-brown colour, the dye apparently being an aniline dye of coal-tar origin. Spun silk takes the bright colours made from aniline very well, but the use of articles so dyed is dangerous. In the museum of the College of Surgeons are preserved some brightly-coloured children's socks, which gave rise to a similar affection on the feet of a child (I believe in France). I also believe that the late Marquis of Hastings was once similarly affected. 